\title{
Anticorrosion Nanocrystalline Beta Zeolite Thin Film for Advanced Applications
}

\author{
Maha Saud M. Al-subaie, Aisha Mahmood A. Al-Turkustani, \\ Rosilda Selvin, and Saedah Rwede Al-Mhayawi \\ Chemistry Department, Faculty of Science for Girls, King Abdulaziz University, P.O. Box 80200, Jeddah 21589, Saudi Arabia \\ Correspondence should be addressed to Aisha Mahmood A. Al-Turkustani; a.m.turkustani@hotmail.com
}

Received 16 December 2014; Accepted 6 January 2015

Academic Editor: Vijay K. Thakur

Copyright (C) 2015 Maha Saud M. Al-subaie et al. This is an open access article distributed under the Creative Commons Attribution License, which permits unrestricted use, distribution, and reproduction in any medium, provided the original work is properly cited.

\begin{abstract}
Steel alloys corrosion is ubiquitous and is conventionally protected by anticorrosion chromate coatings. However, the process suffers from the release of carcinogenic hexavalent chromium ions that needs to be replaced by an ecofriendly alternative. In this context, the need for the development of satisfactory ecofriendly chromium-free coating with superior corrosion performance is highly desirable. In the present study, we synthesized fully dispersible nanocrystalline Beta zeolite seeds and coated on steel alloys followed by steaming. The samples were characterized by XRD, FE-SEM, and DLS analyses. The anticorrosion behavior of the synthesized nanoparticle coatings on steel alloys was investigated by electrochemical measurements (DC polarization) and electrochemical impedance spectroscopy (EIS) in $\mathrm{NaCl}$ and acid and alkaline media under identical experimental conditions. The present study demonstrated that the nanozeolite coating can be a potential alternative for toxic and carcinogenic chromate coating.
\end{abstract}

\section{Introduction}

Metal corrosion is inevitable and can be controlled and managed. There are direct and indirect expenses due to corrosion control. Every year billions of dollars are used for corrosion control. Therefore, corrosion control is very important to protect the environment and economy. Current method of steel corrosion control method uses chromate coating and is unacceptable due to their carcinogenic nature. Hence, a chromium-free technology with superior corrosion performance is highly desirable. In this context, there is obviously a need for more environmentally friendly corrosion-resistant coating materials such as polymers and inorganic materials. It is evident from the literature that the electrochemical deposition of conductive polymer coating suffers from low thermal stability and adhesion [1-3]. Sol-gel coatings have been found to be a promising alternative to chromate conversion coating due to their superior adhesion, good barrier properties, and high chemical and thermal stability $[4,5]$. Solgel coatings of zirconia [6,7], silica [8], silica-titania [9], silica-alumina [8], and silanes [10] have been tried to replace chromium based coatings. But inorganic coatings are easy to crack and need high curing temperature [11, 12]. This problem can be solved by making organics-inorganic hybrid coating. Recent advances in nanotechnology have provided a variety of options for novel coatings capable of preventing or reducing corrosion [13]. It has been demonstrated recently in the literature that a dense coating of zeolite offers a remarkable corrosion resistance for steel and aluminum alloys [14-17]. The idea of using zeolites for anticorrosion materials stems from the well-known facts about zeolites such as being nontoxic and being used in food and drug applications [18].

Zeolites are crystalline aluminosilicate materials, whose rigid structures define channels and cavities of strictly regular dimensions called micropores. Driven by a wide choice of applications and a multitude of challenges nanosized zeolites presented to materials scientists, nanocrystalline zeolites can be used in a variety of new and existing applications as in catalysts, ion exchangers, antibacterial materials, sensors, optical devices, anticorrosion, and so forth. There has been a rapid progress on the development of zeolite thin film 
for anticorrosion application. The method of preparation of zeolite significantly affects the structure and hence the anticorrosion. The anticorrosion efficiency is independent of the thickness of the coatings. It is well documented in the literature that for better performance the zeolite coating should be of less intracrystalline pores and no intercrystalline pores [15-17]. The zeolite coatings are impermeable due to the pores and are blocked by the structure directing agent.

So far the anticorrosion studies are focused on hydrothermally synthesized pure-silica MFI (silicalite-1) system and anticorrosion ability zeolite AEL coating on aluminum alloy by ionothermal method is reported [19]. Zeolite Beta contains aluminum in the framework and is a large-pore material with mutually perpendicular intersecting 12-ring $(5.6 \times 5.6$ and $6.6 \times 6.7 \AA$ ) channels and is traditionally synthesized in a basic medium with $\mathrm{TEA}^{+}$ions as the template.

The present study aims at preparing Beta zeolite thin film on carbon steel by dry gel conversion method and to explore the anticorrosion protection of nanocrystalline zeolite coated carbon steel in aqueous solution.

\section{Materials and Methods}

2.1. Chemicals. Tetraethoxysilane (TEOS), aluminium isopropoxide (AlP), tetraethylammonium hydroxide (TEAOH, $10 \% \mathrm{aq}$ ), and Tween-80 were commercial samples from Merck and were used without further purification. Carbon steel samples were kindly provided by SABIC and were cut into $2 \times 2 \times 0.1 \mathrm{~cm}$ pieces and polished using sand paper. Prior to zeolite coating, it was cleaned with acetone and deionized (DI) water. It was rinsed three times with DI water and dried in air at room temperature.

2.2. Synthesis of Nanocrystalline Zeolite Beta Catalyst. In order to synthesize nanocrystalline Beta zeolite, a hydrolysed clear sol of TEAOH-AlP-TEOS- $\mathrm{H}_{2} \mathrm{O}$ was prepared at room temperature. The molar composition of the final solution was $1 \mathrm{SiO}_{2} / 4 \mathrm{EtOH} / 0.27 \mathrm{TEAOH} / 0.07 \mathrm{AlP} / 20 \mathrm{H}_{2} \mathrm{O}$. The clear sol was concentrated in a rotary evaporator at $80^{\circ} \mathrm{C}$ as described in the literature [20]. The two-thirds of the concentrated precursor sol was transferred into an autoclave and aged at $90^{\circ} \mathrm{C}$ for 3 days. The aged sol was mixed with unaged sample and diluted with ethanol. A small quantity of Tween-80 (polyoxyethylene 80 sorbitan monostearate, Aldrich, Tween$80 / \mathrm{SiO}_{2}=0.01 \mathrm{w} / \mathrm{w}$ ) was added to improve the wetting of the substrate.

The nanoprecursor sol was deposited on the substrate by dip-coating (5-minute immersion). The coated substrate was dried at RT for $24 \mathrm{~h}$ followed by steaming at $180^{\circ} \mathrm{C}$ for $6 \mathrm{~h}$.

The corrosion studies were carried out using a direct current (DC) polarizer equipped with a saturated calomel electrode (SCE) as a reference electrode and a platinum wire as an auxiliary electrode. The working electrode was either a coating-free or zeolite coated carbon steel substrate immersed in $50 \mathrm{~cm}^{2}$ in the solution. The corrosion behavior was studied using an aqueous solution of either a $0.1 \mathrm{M}$ $\mathrm{NaCl}, 0.1 \mathrm{M} \mathrm{H}_{2} \mathrm{SO}_{4}$, or $0.1 \mathrm{M} \mathrm{HCl}$ at room temperature. The potentiodynamic polarization scans began at $-150 \mathrm{mV}$ versus
TABLE 1: The DLS result of nanocrystalline Beta synthesis.

\begin{tabular}{lcc}
\hline Sample number & Sample name & Size $(\mathrm{nm})$ \\
\hline 1 & NPs & 5.1 \\
2 & Aged NPs & 20 \\
3 & NZs & 45.0 \\
\hline
\end{tabular}

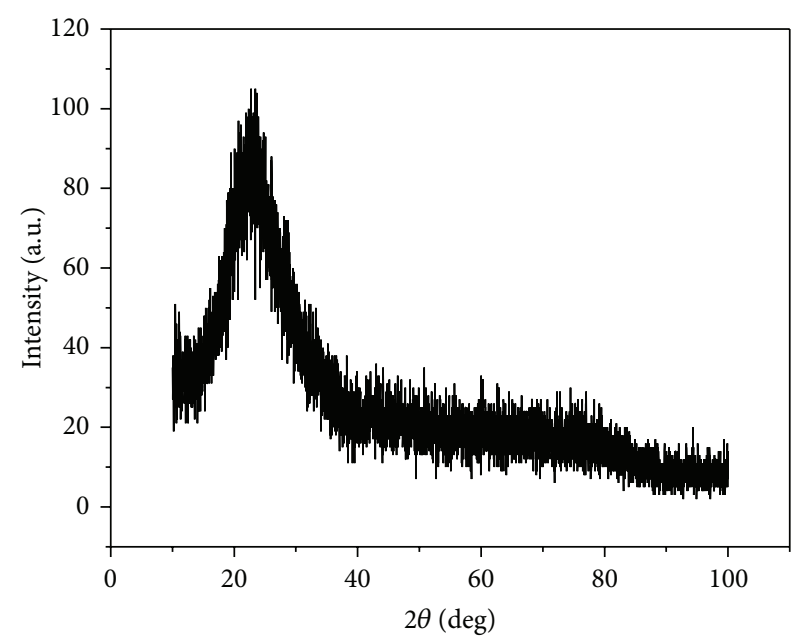

FIGURE 1: X-ray diffraction patterns of the nanocrystalline Beta zeolite.

SCE with a stabilization time of 15 minutes and continuously in the anodic direction at $10 \mathrm{mV} \mathrm{s}^{-1}$.

2.3. Characterization. Powder X-ray diffraction patterns were recorded on a Regaku 2000 diffractometer using $\mathrm{Cu}$ $\mathrm{K} \alpha$ radiation from $2 \theta=5$ to $30^{\circ}$ at a scan rate of $2^{\circ} / \mathrm{min}$ with a step size of $0.04^{\circ}$. Morphology and particle size of the zeolite nanocrystals were examined with TEM (JEM-2010, $200 \mathrm{kV}$ ) analyses. For TEM analysis, a drop of the diluted solution ( $0.0005 \mathrm{wt} \% \mathrm{~g} /$ water) was placed (a drop of ethanol was placed and dried before placing sample) on carbon coated copper grid. The particle size distribution was studied by DLS (DLS, ZetaSizer-3000 with a $10 \mathrm{Mw} \mathrm{He}-\mathrm{Ne}$ Laser from Malvern Instrument Co.).

\section{Results and Discussion}

3.1. DLS Measurement. The particle sizes of the zeolite were determined by DLS measurement. A few drops of the zeolite sample were diluted with water and evaluated by DLS analysis. The results are shown in Table 1 . The concentrated nanoprecursor sample after ageing at $90^{\circ} \mathrm{C}$ for 3 days is about $20 \mathrm{~nm}$. The size of the final nanoparticles in the coated substrate after steaming at $180^{\circ} \mathrm{C}$ for $6 \mathrm{hrs}$ is about $45 \mathrm{~nm}$.

3.2. XRD Analysis. The $\mathrm{XRD}$ analysis results of sample are shown in Figure 1.

The interplanar spacings calculated from the XRD patterns compare well with the reported values for zeolite Beta. 
TABle 2: Corrosion parameters derived from the polarization curves of bare and coated alloy plates in $\mathrm{NaCl}_{2} \mathrm{H}_{2} \mathrm{SO}_{4}$, and $\mathrm{NaOH}$ solutions.

\begin{tabular}{|c|c|c|c|}
\hline Sample ID & $E_{\text {corr }}(\mathrm{V} / \mathrm{SCE})$ & $\log i_{\text {corr }}\left(\mathrm{A} / \mathrm{cm}^{2}\right)$ & Corrosion rate (mm/year) \\
\hline \multicolumn{4}{|c|}{$3 \mathrm{wt} \% \mathrm{NaCl}$ solution } \\
\hline TC1010 & -543.51 & -3.52 & 0.0034593 \\
\hline BZTC1010 & -660.2 & -3.54 & 0.0032988 \\
\hline \multicolumn{4}{|c|}{$0.1 \mathrm{M} \mathrm{H}_{2} \mathrm{SO}_{4}$ solution } \\
\hline TC1010 & -517.61 & -0.82 & 1.7257 \\
\hline BZTC1010 & -498.62 & -1.41 & 0.4526569 \\
\hline \multicolumn{4}{|c|}{$0.1 \mathrm{M} \mathrm{NaOH}$ solution } \\
\hline TC1010 & -297.33 & -3.28 & 0.0059535 \\
\hline BZTC1010 & -244.39 & -3.83 & 0.0016986 \\
\hline
\end{tabular}

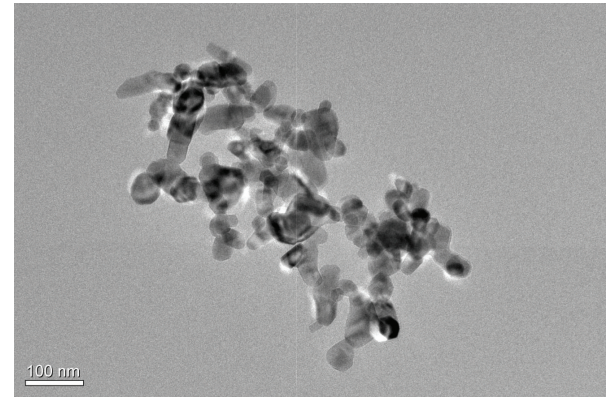

FIGURE 2: TEM images of the nanocrystalline Beta zeolite.

Due to the small size of the crystals, however, the XRD peaks are broadened.

3.3. TEM and SEM Analyses. The TEM micrographs of the sample prepared by dry-gel conversion method are presented in Figure 2. As seen in the micrograph, the crystal size is about $45 \mathrm{~nm}$. The FE-SEM images of the Beta zeolite steel samples before and after steaming (Figure 3) show that the nanoparticles are more uniform after steaming. It is believed that during steaming process silica dissolution and crystallization produced more uniform nanoparticles.

3.4. Corrosion Behavior of the Zeolite Coating. The corrosion behavior of nanocrystalline Beta zeolite films was studied under kinetic control conditions. The previous anticorrosion study on zeolite coated metal substrate shows that the corrosion resistance of the zeolite coating is independent of the thickness of the coatings and the corrosion resistance is good for the zeolite coating with minimal intracrystal porosity [1417]. It is also reported that the as-synthesized zeolite coating gives better corrosion resistance. In our study, we adopted these findings and used a fully dispersible nanocrystalline Beta zeolite of $15 \mathrm{~nm}$ size for coating. During coating, onethird of unaged zeolite nanoprecursor solution $(5.1 \mathrm{~nm}$ size particles) is mixed with two-thirds of aged $\left(90^{\circ} \mathrm{C}\right.$ for 3 days) nanoprecursor solution ( $20 \mathrm{~nm}$ size particles) and coated on carbon steel. The unaged nanoprecursor solution which has plenty of surface hydroxyl groups helps to adhere the nanoparticles strongly on the substrate. A small quantity

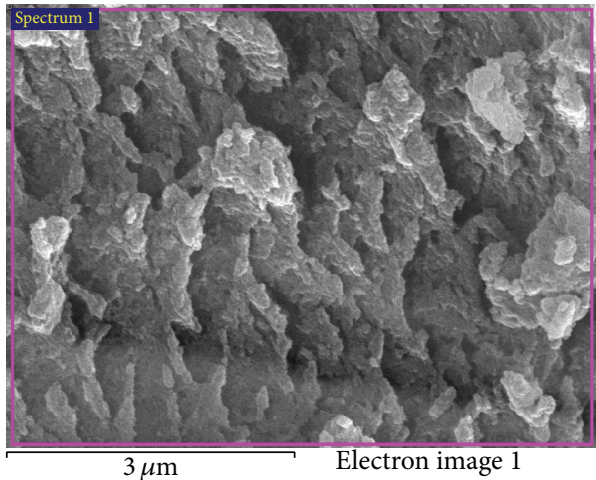

(a)

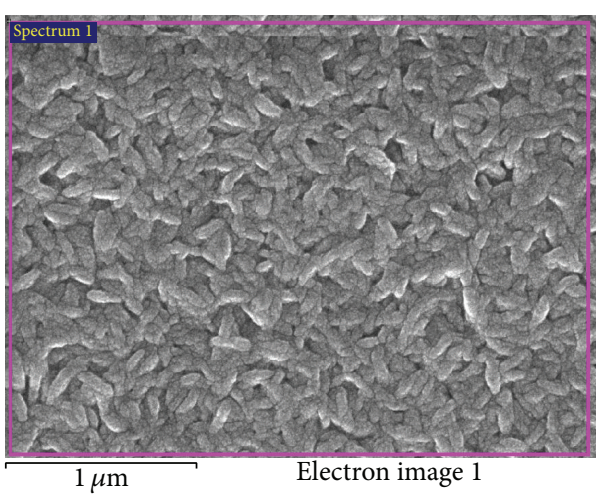

(b)

FIGURE 3: FE-SEM images of nanocrystalline Beta zeolite thin film. (a) Before steaming; (b) after steaming.

of Tween-80 is added for better wetting of nanoparticle solution. The coated samples are placed on an autoclave and steamed at saturated water vapor pressure. It is believed that during steaming process intergrown nanocrystal makes the zeolite coating denser with minimal intracrystal porosity. The sample after steaming at $180^{\circ} \mathrm{C}$ for $6 \mathrm{~h}$ showed a particle size of $45 \mathrm{~nm}$. Figure 4 gave the Tafel plots of nanocrytalline Beta zeolite coating by dry gel conversion method in aqueous solution of sodium chloride, sodium hydroxide, and sulphuric acid. The corrosion properties of the zeolite coated samples were summarized in Table 2. As given in Table 2 


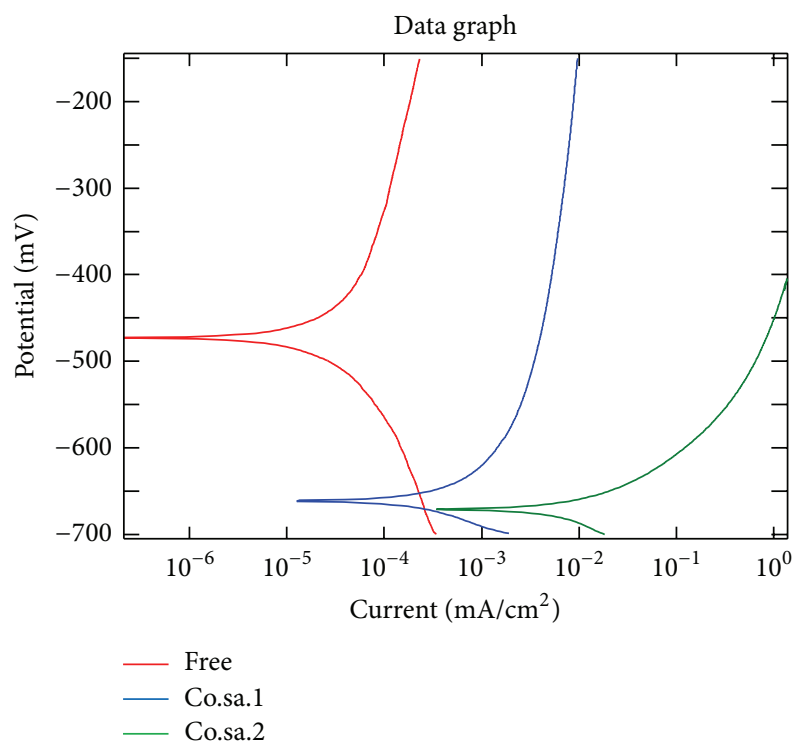

(a)

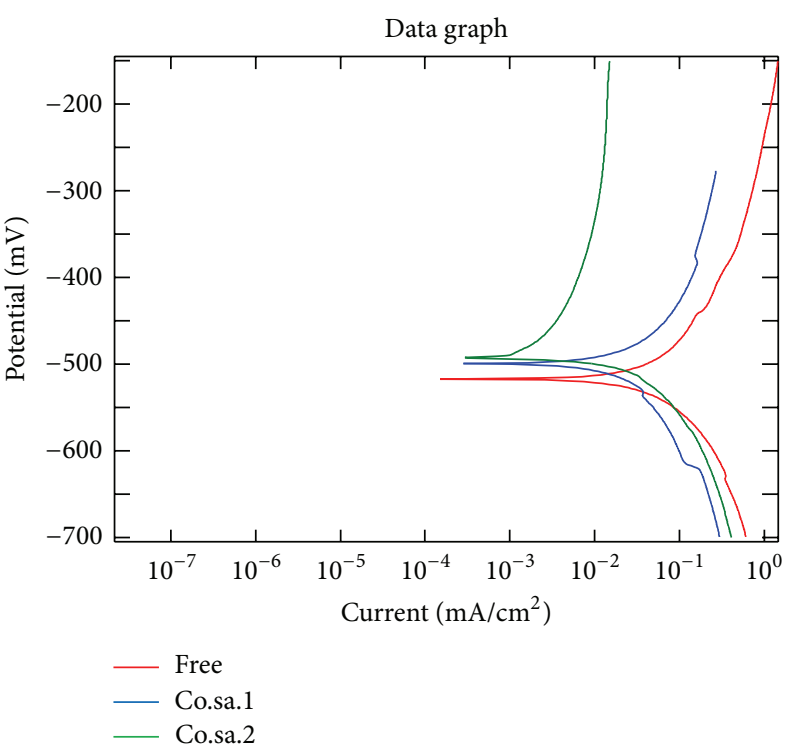

(b)

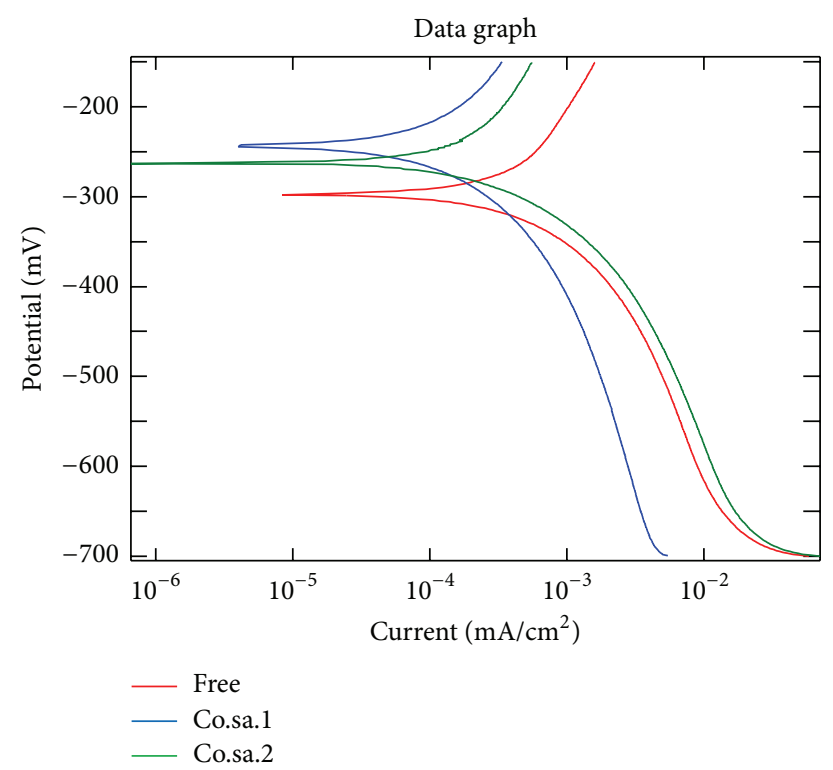

(c)

FIGURE 4: Comparison of the anticorrosion zeolite coatings produced by the in situ crystallization and the dry-gel-conversion processes in (a) $3 \% \mathrm{NaCl}$ solution; (b) $0.1 \mathrm{M} \mathrm{H}_{2} \mathrm{SO}_{4}$; and (c) $0.1 \mathrm{M} \mathrm{NaOH}$ solution.

corrosion potential $\left(E_{\text {corr }}\right)$ of the zeolite coated samples showed corrosion resistance in aqueous solution of sodium chloride, sodium hydroxide, and sulphuric acid. The anticorrosion ability of the zeolite coating is clearly seen from the $E_{\text {corr }}$ values of the bare and the zeolite coated film. The corrosion resistance of zeolite coated film on sulphuric acid is very high compared to other solutions. The current study shows that large pore zeolites are also capable of protecting carbon steel in various corrosion solutions. The zeolite coating synthesis method adopted here is simple and fast. The reproducibility of the nanozeolite coating procedure is excellent.

\section{Conclusions}

In the present study we have prepared nanocrystalline Beta zeolite coated carbon steel by dry-gel conversion method. The zeolite coated carbon steel plate was characterized by DLS, XRD, and SEM. The result showed that the Beta zeolite nanoparticles are crystalline and are about $15 \mathrm{~nm}$. The corrosion resistance of zeolite coated film in the solution understudied is sulphuric acid $>$ hydrochloric acid $>$ sodium chloride. The method can be extended to larger substrates and can be a potential alternative for toxic and carcinogenic 
chromate coating. The present method of preparing anticorrosion zeolite coating could be able to protect the steel alloy samples from corrosion so that environment and economy will be managed.

\section{Conflict of Interests}

The authors have declared that there is no conflict of interests.

\section{Acknowledgment}

The authors would like to thank Department of Chemistry, King Abulaziz University (Girls Campus), for providing the required facilities.

\section{References}

[1] D. W. DeBerry, "Modification of the electrochemical and corrosion behavior of stainless steels with an electroactive coating," Journal of the Electrochemical Society, vol. 132, no. 5, pp. 10221026, 1985.

[2] G. M. Spinks, A. J. Dominis, G. G. Wallace, and D. E. Tallman, "Electroactive conducting polymers for corrosion control," Journal of Solid State Electrochemistry, vol. 6, no. 2, pp. 85-100, 2002.

[3] S. C. Yang, R. Brown, R. Ractcot, Y. Lin, and F. McCladnon, "Electroactive polymer for corrosion inhibition of aluminum alloys," in Electroactive Polymers for Corrosion Control, vol. 843 of ACS Symposium Series, chapter 13, pp. 196-206, 2003.

[4] A. Duran, Y. Castro, M. Aparicio, A. Conde, and J. J. de Damborenea, "Electrochemical behavior of silica basic hybrid coatings deposited on stainless steel by dipping and EPD," International Materials Reviews, vol. 52, article 157, 2007.

[5] M. Guglielmi, "Sol-gel coatings on metals," Journal of Sol-Gel Science and Technology, vol. 8, no. 1-3, pp. 443-449, 1997.

[6] R. L. Twite and G. P. Bierwagen, "Review of alternatives to chromate for corrosion protection of aluminum aerospace alloys," Progress in Organic Coatings, vol. 33, no. 2, pp. 91-100, 1998.

[7] T. L. Metroke, R. L. Parkhill, and E. T. Knobbe, "Passivation of metal alloys using sol-gel-derived materials-a review," Progress in Organic Coatings, vol. 41, no. 4, pp. 233-238, 2001.

[8] D. Wang and G. P. Bierwagen, "Sol-gel coatings on metals for corrosion protection," Progress in Organic Coatings, vol. 64, no. 4, pp. 327-338, 2009.

[9] M. Atik, P. de Lima Neto, M. A. Aegerter, and L. A. Avaca, "Solgel $\mathrm{TiO}_{2}-\mathrm{SiO}_{2}$ films as protective coatings against corrosion of $316 \mathrm{~L}$ stainless steel in $\mathrm{H}_{2} \mathrm{SO}_{4}$ solutions," Journal of Applied Electrochemistry, vol. 25, no. 2, pp. 142-148, 1995.

[10] L. M. Palomino, P. H. Suegama, I. V. Aoki, M. F. Montemor, and H. G. de Melo, "Electrochemical study of modified nonfunctional bis-silane layers on Al alloy 2024-T3," Corrosion Science, vol. 50, no. 5, pp. 1258-1266, 2008.

[11] M. L. Zheludkevich, I. M. Salvado, and M. G. S. Ferreira, "Sol-gel coatings for corrosion protection of metals," Journal of Materials Chemistry, vol. 15, no. 48, pp. 5099-5111, 2005.

[12] A. Mitra, Z. B. Wang, T. G. Cao, H. T. Wang, L. M. Huang, and Y. Yan, "Synthesis and corrosion resistance of high-silica zeolite MTW, BEA, and MFI coatings on steel and aluminum," Journal of the Electrochemical Society, vol. 149, no. 10, pp. B472-B478, 2002.
[13] R. L. Cook and A. W. Myers, "Nanoparticle surface modification for advanced corrosion inhibiting coatings," in Nanotechnology Applications in Coatings, vol. 1008 of ACS Symposium Series, chapter 5, pp. 64-88, American Chemical Society, Washington, DC, USA, 2009.

[14] P. C. Banergee, R. P. Woo, S. M. Grayson, A. Majumder, and R. K. S. Raman, "Influence of zeolite coating on the corrosion resistance of AZ91D magnesium alloy," Materials, vol. 7, no. 8, pp. 6092-6104, 2014.

[15] X. L. Cheng, Z. B. Wang, and Y. S. Yan, "Corrosion-resistant zeolite coatings by in situ crystallization," Electrochemical and Solid-State Letters, vol. 4, no. 5, pp. B23-B26, 2001.

[16] D. E. Beving, A. M. P. McDonnell, W. Yang, and Y. Yan, "Corrosion resistant high-silica-zeolite MFI coating: one general solution formulation for aluminum alloy AA-2024-T3, AA5052-H32, AA-6061-T4, and AA-7075-T6," Journal of the Electrochemical Society, vol. 153, no. 8, pp. B325-B329, 2006.

[17] W.-C. Changjean, A. S. T. Chiang, and T.-C. Tsai, "Anti-corrosion zeolite film by the dry-gel-conversion process," Thin Solid Films, vol. 529, pp. 327-332, 2013.

[18] J. H. Han, "Antimicrobial food packaging," Food Technology, vol. 54, no. 3, pp. 56-65, 2000.

[19] R. Cai, M. Sun, Z. Chen et al., "Ionothermal synthesis of oriented zeolite AEL films and their application as corrosionresistant coatings," Angewandte Chemie-International Edition, vol. 47, no. 3, pp. 525-528, 2008.

[20] C.-Y. Hsu, A. S. T. Chiang, R. Selvin, and R. W. Thompson, "Rapid synthesis of MFI zeolite nanocrystals," Journal of Physical Chemistry B, vol. 109, no. 40, pp. 18804-18814, 2005. 

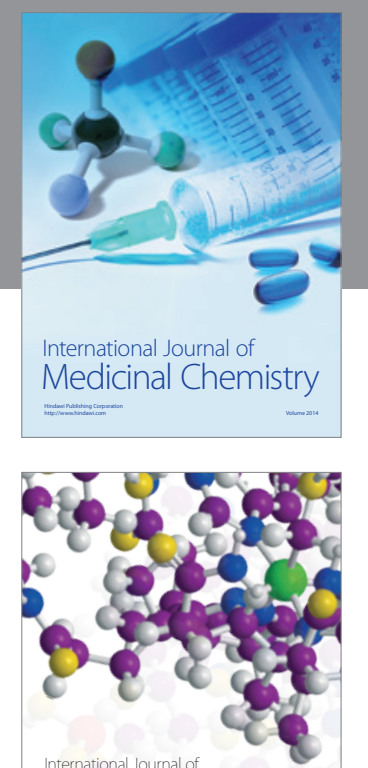

\section{Carbohydrate} Chemistry

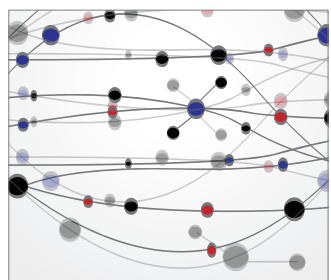

The Scientific World Journal
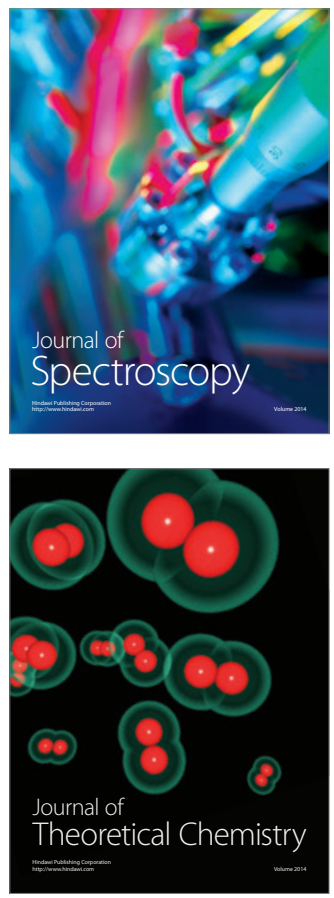
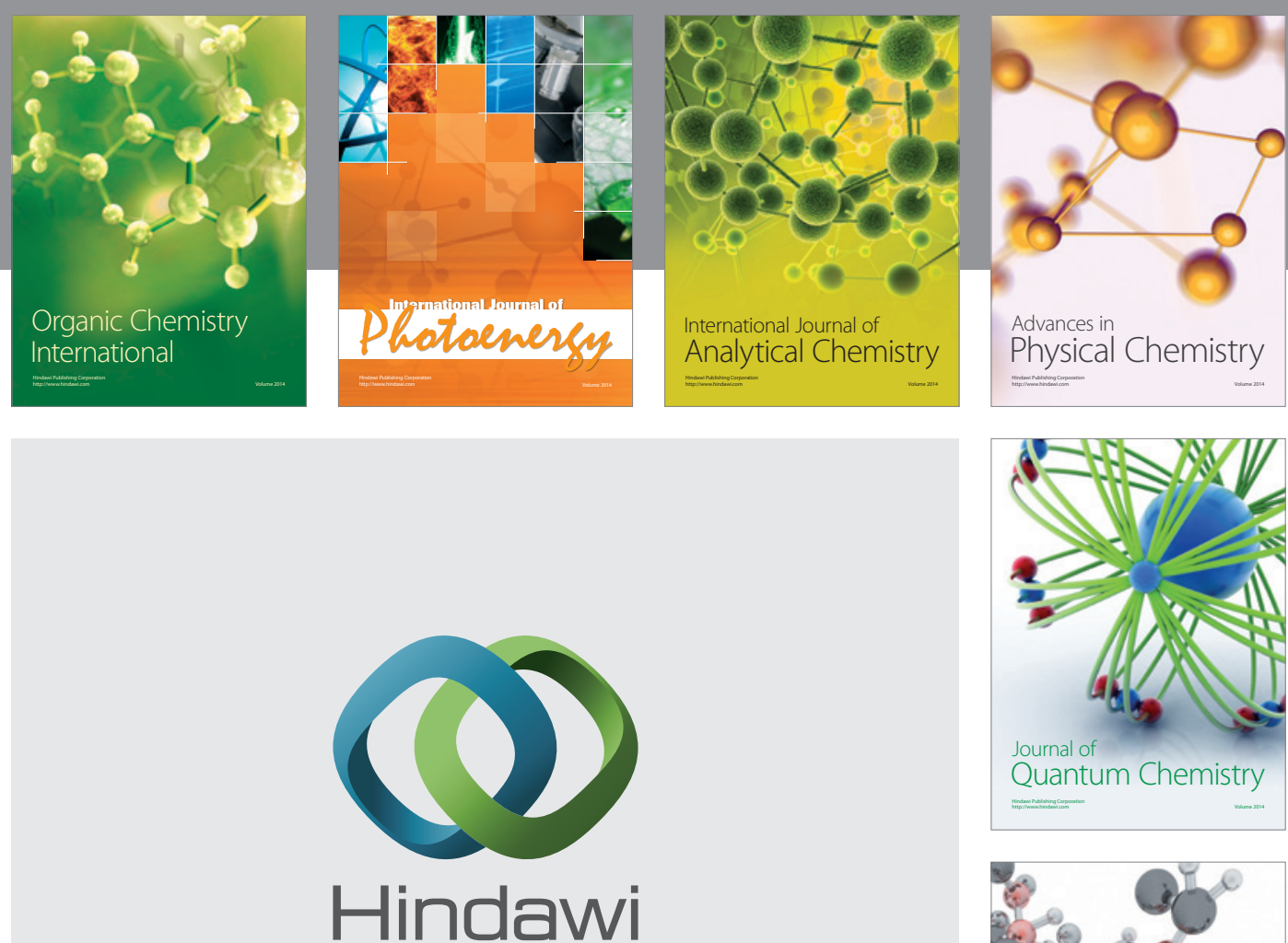

Submit your manuscripts at

http://www.hindawi.com

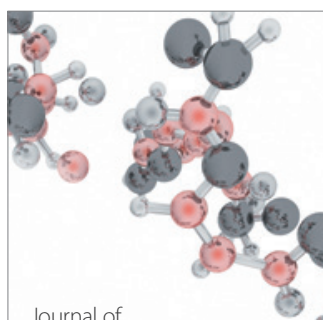

Analytical Methods

in Chemistry

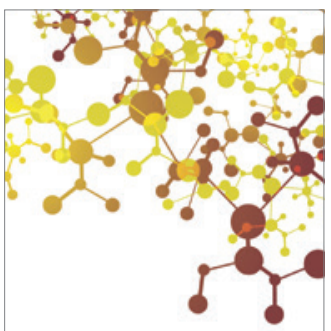

Journal of

Applied Chemistry

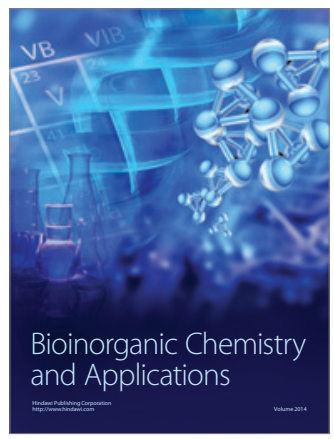

Inorganic Chemistry
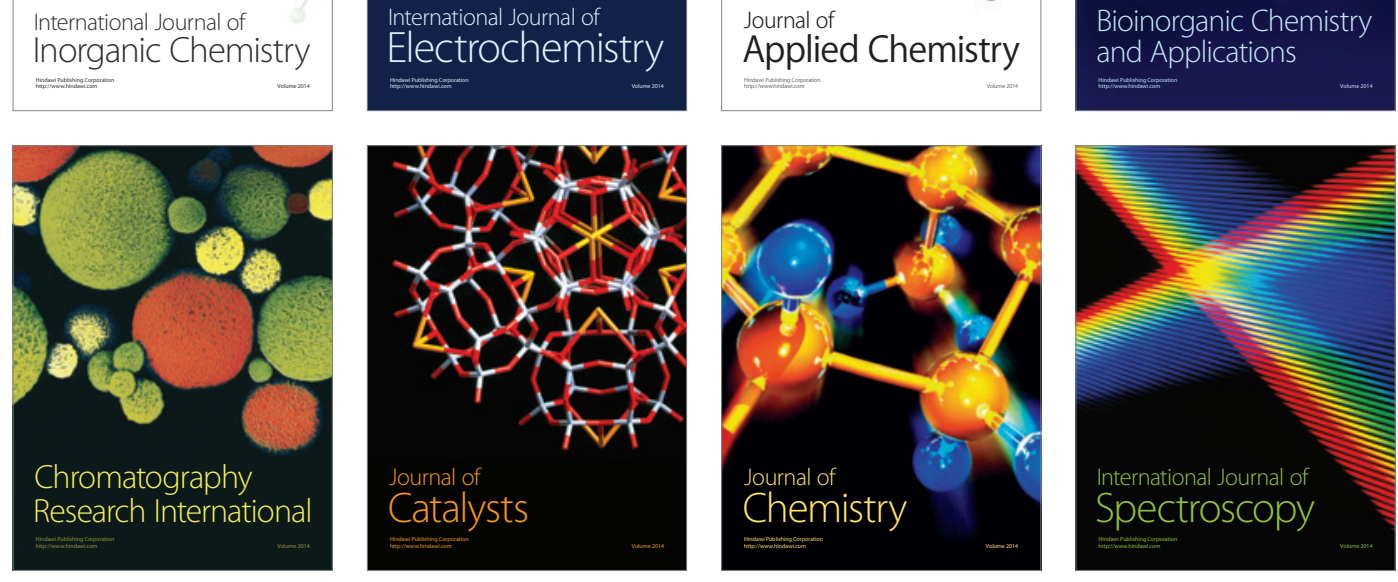